\title{
Primary caregivers perceptions of the role of fathers in the provision of nutritional care in a resource constrained environment in Cape Town, South Africa
}

Melissa Judith Brown ( $\square$ melissajudithbrown@gmail.com )

University of the Western CApe https://orcid.org/0000-0002-0375-4057

Nicolette Roman

University of the Western Cape

Research article

Keywords: perceptions, nutrition, food, feeding, parenting, caregivers

Posted Date: November 21st, 2019

DOI: https://doi.org/10.21203/rs.2.13975/v3

License: (c) (1) This work is licensed under a Creative Commons Attribution 4.0 International License.

Read Full License 


\section{Abstract}

Background: The role of fathers has traditionally been defined as a breadwinner or provider, with men generally having lower levels of engagement in childcare tasks, especially with young children. The involvement of fathers has important consequences for child well-being, especially with regards to issues of diet/nutrition, exercise, play, and parenting behaviours. This paper seeks to explore the perceptions and limitations that primary caregivers have on fathers' provision of care in a resource constrained community in South Africa. Methods: Data was collected through in-depth face to face interviews, with a sample of 10 primary caregivers in a resource constrained community in Cape Town, South Africa. Results : The findings reveal that there is a lack of involvement from fathers in the provision of nutritional care and that this affects mothers and grandmothers who then need to provide both the physical and emotional care to their children. These findings are based on the perspective of mothers and grandmothers and their perceived roles in the family. Conclusion : The level of lack of financial involvement from fathers has dramatically affected the participating family's food security due to only one member in the household earning below minimum wage. This has therefore meant that the dietary needs of the family are not being met with nutritional foods, but instead by high fat and high sugar content foods. The findings also highlighted that primary caregivers want to be taught about health and nutritional food choices for a limited budget.

\section{Background}

Traditionally the role of fathers has been defined as breadwinner or provider with men being less involved in tasks with their younger children. (1). Father involvement has many needed consequences for the well-being of children specifically with regards to issues of diet/nutrition, exercise, play, and parenting behaviours (eg, reading, discipline) (2).

Family studies have concentrated on the influences of maternal responsibilities or combined data of both parents (3). However, there is a lack of studies on the influence of fathers to inform a view point of the vaires effects of fathers on young children's health behaviours (3). This scenario is likely the result of older and traditional ideas of parental roles where mothers are considered caretakers with fathers seen as the breadwinners and head of the house (3). The involvement of fathers in parenting has been associated with greater positive outcomes in child development on a cognitive and socio-behaviour level. As a result there is a positive improvement in "preterm infants weight, breastfeeding rates, higher receptive language skills and higher academic achievement" (4). The global increase in the lack of involvement of fathers in children's lives and the effect it has on them needs to be highlighted (1).

In 2013 South Africa's an estimated 14.3 million households consisted of 18.6 million children and 34.4 million adults, of these children, 7.3 million (39.5\%) lived only with their mothers, while $3.3 \%$ of children resided only with their fathers (5). Statistics South Africa (2014) estimated the number of fathers not residing in the same household as their children and who are not present in their lives to be about $46.22 \%$. The same report indicated 4.1 million (22\%) of children in South Africa did not live with either parent. 
Numerous reasons have been reported which affect where fathers are able to stay and why they do not live with their family such as "Unemployment, poverty, income inequality, gender power, consequences of intimate partner violence, masculinity ideologies, migration and abandonment" (6). Globally, it is estimated that the average time women spend daily in caring for the home and children is "three times what men spend", but this varies dramatically across settings (7).

An analysis of statistics from around the world determined that the ratio of women's time spent on unpaid work (own family caregiving) to men's is a great deal greater in low-and lower-middle income nations (7). This difference shows that poverty dramatically increases gender inequalities in unpaid care, with the poorest women spending the most time in unpaid care giving tasks (7). Father care giving needs to be seen in the context of unpaid care as well (8).

The catering of childcare needs in South Africa has been described "quantitatively using data collected in Time Use Surveys (TUS)" (8) with the students being conducted in 2000 and 2010. In both surveys it showed that women spent considerably more time on childcare than men (8). The 2000 TUS reported that "among adults (aged 21-55) who live with at least one child, women spend an average of 5.9 hours per week on childcare compared with 0.6 hours spent by men" (8). Similarities in gender differences were identified in the 2010 survey, stated that the "average amount of time that women spend on childcare is more than eight-times greater than the time spent by men" (9).

In South Africa there are low rates of paid child maintenance and distressing rates of gender-based violence especially that of neglect and abuse of children by men (10). It is reported that South Africa has "one of the highest rates of violence" against women "in the world", second highest rate of father abuse in Africa, with its neighbouring country Namibia being the highest (11).

Racial dynamics also seem to come into play when fathers are absent from the household (11). Across South Africa, Black African fathers have the highest rate of absence from their households at $41.92 \%$ (9). In the Western Cape specifically, Coloured fathers are most affected (due to the higher Coloured population), with $20.91 \%$ of fathers not being present, or living in in their household (10). Black African fathers were second followed by White fathers with $14.46 \%$ and $2.21 \%$ fathers not present and not living in the household (10). Absent fathers create problems ranging from broken families, aggressive behaviour among children, economic and social problems and in some cases extreme poverty (5). The absence of fathers results in most households being run by single mothers and grandparents (11), who are often reliant on the state's social security system. South Africa's extensive social security system includes a monthly Child Support Grant (12) with the number of social grants increasing "exponentially over the past twenty three years: from an estimated 4 million in 1994 to 17,4 million by October 201"7 (13).

Socioeconomic inequalities in childhood are linked to both "childhood and adult health inequalities" (14). These inequalities correlate with deficiencies in nutrition based on diet quality (15). Diet quality is consistently associated with poor health outcomes such as "obesity, type II diabetes, cardiovascular disease and several cancers" (16). Recent research highlights the high cost of nutrient-rich foods and the 
low cost of nutrient-poor foods, which impacts diet quality and health. Parents end up having to negotiate food purchases on a limited budget (15). This in turn lays the foundation for the feeding practices parents then adopt.

The interrelation between parental feeding practices and children's eating patterns described in the literature by Lipowska and colleagues apply to the attitudes and practises of mothers as the being the focal caregiver, with minimal attention being placed on fathers (17). It has been said that

Mothers generally have a major impact on the expansion of children's eating behaviour as they are more involved in food-related, and structure of mealtimes, while fathers are not part of this decision making process and preperation (17). Unhealthy food likes by mothers (e.g., fast foods, sweets and higher-energy fluids) as well as the access in the home to non-nutritional foods, were found to be the reason for children's preferences when it came to the selection and eating of unhealthy foods (17). It has been found that maternal obesity provides a significant predictor of childhood obesity (17). It is important to recognise that fathers' attitudes and practices may also lead to an increase in a child's desire for unhealthy eating habits, a decrease in general well-being , although mothers and fathers may differ in their approaches (17).

Strategies to feeding used by mothers and fathers are based on many elements (18). Ranging from personal weight-related experiences, "perception of their child's BMI, or the parent's beliefs about gender differences regarding dieting and physical attractiveness" (17). Child obesity research shows greater focus being made on the role of mothers and mothering, with less attention on the influence, roles and responsibilities of fathers in the provision of the family's food availability and choices (18). A landmark survey for South Africa conducted in 2012 indicated that as many as $28 \%$ of South African households were at risk of hunger while $26 \%$ experienced hunger (19). The South African National Health and Nutrition Examination Survey (SANHANES) concluded that undernutrition was high and the prevalence of stunting at $27 \%$ for children under three (19). Children under 14 which made up $16 \%$ of the study population were recorded as being underweight and of these children about one in a hundred severely underweight (19). Overweight and obese children were also found in the survey with $19 \%$ of children aged between two to five being classified as overweight and 5\% classified as obese in 2012 (19). The results dropped slighted in the age groups of six - nine years, but $17 \%$ of children ages ten to 14 years were overweight and nearly $6 \%$ obese (19). Pivotal to this research, the SANHANES study concluded that women mostly do grocery shopping and that the deciding factor on purchasing is the price of food and the distance to travel to shop. Health played lesser deciding factor for most shoppers, especially when men shop (19). The current research study therefore focused on the perceptions of mothers and grandmothers on the provision of nutritional care provided by fathers to their children in a resource constrained community.

\section{Methodology}


This research aimed to develop parental nutritional guidelines to improve nutritional knowledge and feeding practices for children. In this study we selected a qualitative approach to gain a deeper insight into the lives of our target group. A qualitative interpretivist research method was used in this study (20) to explore how the mothers and primary caregivers experience fathers' provision of nutritional care in a resource constrained environment. This allowing for understanding and interpretation, with which the researcher's personal experiences and knowledge could be applied. The interpretations of the researcher were vital to bring "such objectivity to the fore as well as quality of arguments instead of statistical exactness" (1).

\subsection{Participants}

Study participants were mothers and primary caregivers in Manenberg, in the Western Cape Province, South Africa, who care for children between the ages of 3 - 18 years old. The township of Manenberg was chosen because it was a resource constrained environment. It was established in 1966 at the height of the apartheid regime's forced removal programme. Located $20 \mathrm{~km}$ from Cape Town city centre, Manenberg struggles with gangs, drugs and high unemployment (21). The 2011 census shows its population at over 61000 , of whom $85 \%$ were identified as Coloured and $10 \%$ as African. Of this population, 40452 are 'working age' (15-64). Amongst this working age group, 35\% (13 962) were classified as employed, 20\% (7 923) as unemployed, and 46\% (18 567) as 'not economically active.' $61 \%$ of households have a monthly income of less than R3200, and 38\% a monthly income of R1600 or less (22). With regards to Coloured men, who were the target population of this study due to the mothers and grandmothers interviewed, there is limited contemporary research. Research that has been undertaken has focused on Coloured masculinity as violent, uncaring, and absent (23-26).

In order to recruit participants for the study, letters were sent to three local schools, regarded as safe zones by the community, with less likelihood of gang related violence. Of these, one school reported back in the required time period that mothers and caregivers were willing to attend interviews. On the day, 15 mothers/ caregivers (grandmothers) arrived, however, five participants had to leave early, and three mothers that had confirmed did not participate due to gang violence the night before. A total of six grandmothers and two mothers where interviewed.

Table 1 provides a breakdown of the participants, showing the employment status of the mothers and primary caregivers. The households consist of a minimum of eight and a maximum of 11 occupants, including family and extended family. Of the ten interviewees, only three fathers were currently providing financial care to their children.

Family composition, living arrangements and parental practices did not vary significantly across the participant sample. Many of the families consisted of more than eight living in one house (5 - 7 children, plus the primary caregivers and extended family). 
Table 1. Sample Characteristics

\begin{tabular}{|c|c|}
\hline \multicolumn{2}{|l|}{ Interviewees $(\mathrm{n}=10)$} \\
\hline Gender & Female: 10 \\
\hline Grandmothers & 6 \\
\hline Mothers & 4 \\
\hline Mean age & 45.5 \\
\hline Participants highest qualification & Grade 11 \\
\hline Participants lowest qualification & Grade 9 \\
\hline Employment status of mother/caregiver & 7 \\
\hline Fathers living at home & 3 \\
\hline Fathers employment status & 3 \\
\hline Fathers providing financial care & 3 \\
\hline $\begin{array}{l}\text { Maximum number of people living in the } \\
\text { home }\end{array}$ & $\begin{array}{l}>8,<11 \text { occupants family and extended } \\
\text { family. }\end{array}$ \\
\hline
\end{tabular}

\subsection{Data collection}

An interview schedule set up to guide the interview process. Interviews included open-ended questions about respondents' perception of care, difficulties and barriers to parenting, grocery shopping and meal patterns, food-provisioning priorities, fathers constraints and ideals; and the role of fathers in their children's lives. Questions focused on the children in the target age range (3-18 years old). If children fell outside this age range, questions centred on the child closest to it (this happened 3 times). The questionnaire included a set of questions on parent/caregiver-child relationships and parental/caregiver involvement in personal matters and saturation was reached. The interviews were conducted in Afrikaans and English and were recorded. The recordings were later transcribed verbatim by the interviewer.

\subsection{Data analysis}

A thematic analysis was carried out on the transcribed interviews to identify patterns or themes (27), with the findings sorted according to their themes. A table was used for the grouping of main themes as well as proposed sub - themes (27). Additional information was presented using direct quotes from participants and from supporting literature. 


\section{Results}

The results in this study focus on mothers and grandmothers' perceptions of fathers' provision of care in relation to nutritional care. There were five themes identified, with each having either two to three subthemes. Key parts of these findings focused on parental care in general - how mothers perceived care by fathers, healthy diets, as well as resources for nutritional support for mothers. The participants were vocal in the interviews, with some highlighting the effect of gangsterism and drugs on their family environment. Through their participation in the current study, two primary caregivers received information for social services in the area that could provide support to the families.

\section{The perception of care}

The results show that all 10 participants were able to provide a thorough understanding of what constitutes adequate care for children. Two mothers reported:

"I provide the children with attention, food and clothing. I ask them questions about their day and what is happening in their lives. Take care of them when they are sick, sing songs with them. Do activities with them."

(Mother: age 39, Participant 3, three children - ages 7, 10, 16 years old, father unemployed but at home.)

"Supporting him on different levels: financial support, social support, emotional support, listening to him, sitting down when he needs to talk to me. Not just him, but all my children. One also needs to build trust with your children so that they are able to have freedom to come and speak to you."

(Mother: age 48, Participant 9, five children - ages 14, 19, 21, 25, and 28 years old.)

Similar responses were received from all participants. It was commonly stated that food, shelter and clothing was part of care. However, only one mother expressed that love was part of caring for their child. Barriers to the provision of good care were also noted, including money, the environment, or needing to raise the children alone.

"Stress about money, them getting into drugs or the wrong friends. All these things keep you awake at night."

(Caregiver (grandmother): age 65, Participant 5, six children - ages 7, 10, 12, 15, 17, and 21 years old, different fathers who are drug addicts, only one mother of 2 of the children is present but she is unemployed, all other mothers are not in the household.) 
"Difficulty is not letting them play outside because of the area in which they stay, allowing them to have the freedom to walk to the shop and not to have to worry about them getting hurt, and shot or into gangsterism."

(Grandmother: age 57, Diabetic, Participant 10, seven children - ages 5, 7, 10, 12, 15, 17, and 21 years old, parents drug addicts, only one mother of 2 of the children is present)

"Since her father has passed, she does not want to really focus on her schoolwork - almost like she has become lazy with her school work which has made it a little difficult. We shout and argue all the time. Shame she is also very big for her age, she is even heavier than me. Her father used to spoil her alot as the baby and give her a lot of luxuries."

(Mother: age 48, Participant 9, five children - ages 14, 19, 21, 25, and 28 years old.)

\section{Father's involvement in care and nutritional provision}

Participants reported that fathers' involvement in providing nutritional care and support for their children was limited. This is due to many of the fathers being unemployed or not living with the children. When this occurred, they did not make any provisions for financial support. This lack of financial support often means that mothers and grandmothers need to borrow money or go to bed hungry, which had occurred more than once in the last 6 months of the interviews being conducted. Some participants highlighted food insecurity in the communities as an everyday reality. Other participants became emotional and angry when speaking of the lack of support from the fathers.

"No child support. There is no role of the father being fulfilled. He is not there where the son stays. The son lives with his grandmother, so I send money to her. He just left us all and I couldn't have all the children, so I sent my son to live with his grandmother. But I still send money for his food."

(Mother: age 30, Participant 4, two children - ages 5 and 10 years old.)

"There is no money at times, he is not working so we have gone to other family members or somebody, we try and make a plan. Sometimes if there is not enough, we will go without as long as the children eat something and not go to bed hungry. But there were times when we had nothing to eat because we did not have any work and we couldn't ask any more people. I felt bad. The children eat at school in the morning at the feeding scheme. I just eat what I get, or eat a packet of cheap biscuits with tea, as long as the children eat a meal.

But everyone is suffering and always saying there is no food or just a little in the house, there are so many people in the area borrowing money and food that at the end of the month you have to pay so much back to those you borrowed you have to borrow again. I do not even know where some of the children's fathers are. So maybe they do not care." 
(Grandmother: age 57, diabetic, Participant 10, seven children - ages 7, 10, 12, 15,17 and 21 years old.)

One mother noted that her husband, although unemployed, cooked and did the household shopping while she went to work as a street cleaner.

"My husband is not working so it is almost like he is standing in for me at home. I feel like I need to emotionally support everyone in the house, as they all come to me for everything. He takes care of the house work and cleaning while I go to work so it is like we changed roles for the last few months but you can see it is taking its effect on him, as he always used to provide for the family. Now my husband buys the food, but not really a big shop, not a monthly shop. Just when there is something that is needed at the corner shop. There is not really money for a big shop."

(Mother: age 39, Participant 6, three children - ages 7, 10 and 16 years old. )

Another mother noted that the father was unemployed but did make an effort to find food and care for them if the monthly contribution she brought home was not enough for their basic nutritional needs.

"Their father is in the house, but he does not work now. And so I am the only one who is working. I make about R750 a month which does not stretch very far into the month. The father makes sure that if there is no food in the house that he goes out and looks to borrow or ask somebody else so that the children can eat. He enforces the discipline in the house. He is caring to the needs of the family and I think at this point he is a little depressed as he has been trying to find work."

(Mother: age 39, diabetic, Participant 2 , seven children - ages 3, 6, 10, 13, 19, and 22 years old, all living at home. )

\section{Father's present but not involved}

The notion that fathers need to be supportive and discipline their children in order to instil work ethic and provide encouragement for their children to function well at school was commonly highlighted by mothers and grandmothers.

"Not really supportive fathering or loving at times. Don't recall the father sitting with his son many times, as he would get very angry with him for not being able to grasp things quickly. My husband is at home, he is a father but, provides the money for physical things. He just orders the children around to do things he wants them to do. Our son is forever in trouble at school and then I always have to go."

(Mother: age 42, Participant 1, two children - ages 10 and 16 years old.)

"There is no role of the father being fulfilled he is not there where the son stays. The son lives with his grandmother, so I send money to her." 
(Mother: age 30, Participant 4, two children - ages 5 and 10 years old.)

\section{Capacity building and nutritional understanding of mothers and primary caregivers}

With respect to what food the mothers and grandmothers provide for their children, many indicated there was a need to understand what is healthy. Participants wanted to know how to cook on a limited budget while still make sure their children are getting enough nutrients. The majority of the women interviewed claimed to assume a primary, if not complete responsibility, for managing their family's diet. This included budgeting meals, shopping, preparing and serving meals. Within the participant group, the children's weight seemed to be within the healthy range. However, the mothers and caregivers were suffering from diseases and many were obese. As research has indicated, this could have a future effect on their children, who may end up with similar weight and health problems. Some of the challenges the parents and caregivers face when it comes to eating healthily are shown below:

"How to feed children, because you can make the food but then they do not want to eat what is healthy. I am diabetic and the hospital they gave me a list of what to eat. I cannot buy all those things. It will be too expensive so I try to buy some of the things, then we can all eat healthy but they do not want to eat a lot of veg. They say it doesn't taste nice. Maybe I need to know how to make it differently. Classes where you learn, not just pieces of paper that you throw away. How do I as a diabetic buy good food if it is so expensive."

(Grandmother: age 57, diabetic, Participant 10, seven children - ages 7, 10, 12, 15,17 and 21 years old.)

"How to make good healthy food choices and why. But also a course for everyone in the family so the children also understand why they are being given the food they are given. It is maybe important to know when to buy foods in season and the quantity of food to buy for a family and how then to make sure they are eating enough or too little"

(Mother: age 30, Participant 4, two children - ages 5 and 10 years old).

"Yes, I dish the food and also say they can have a little first and if they finish it and want more, they can have so that we do not waste. I eat whatever there is left or just a lot of white bread and coffee, but I take my medication for my diabetes.

(Mother: age 39, diabetic, Participant 2, seven children - ages 3, 6, 10,12, 14, 19, and 22 years old, all living at home).

Many times women are the main providers of children's diets, and overall - wellbeing, their articulations of men's contributions to food provision offer crucial insights into the power dynamics that produce and sustain the gendered responsibilities of nutritional care work in the family (28). 


\section{Discussion}

In South Africa many parents face considerable barriers to accomplish the tasks of parenting (15). Poverty increases parents' difficulties in providing for and protecting their children, and makes emotionally distant, harsh and inconsistent parenting more likely (15). Parents living in poverty are likely to be less educated and therefore making them limited in being able to support their children's educational development and in some cases demanding nutritional needs (15). This is the case with the participants in this study where the highest qualification held by parents in the group was Grade 11.

Poverty reduces the ability of parents to provide enough and appropriate nutrition for their children (15). As well as the ability to constantly provide good educational opportunities, which is the base necessary for healthy development (15). Low education levels paired with the presence of food insecurity may impact not only the quantity of available food but also diet intake patterns as people chose not to eat as regularly in an attempt to save meals (29). According to Global nutrition report (30), note the number of people who suffer from hunger has increased over the past three years, returning to levels from a decade ago . The number of people in the world affected by undernourishment, or chronic food deprivation, is estimated to have increased by $2.1 \%$ from around 804 million in 2016 to nearly 821 million in 2017 (31). Many food insecure communities have been found to eat less nutritious food, to limit portion sizes, to skip meals sometimes days at a time to deal with food shortages in the household (32). A psychosocial link between food insecurity, obesity and malnutrition along with further metabolic diseases such as diabetes has been found. A report by the Food \& Agricultural Organization (FAO) noted the presence of physiological adaptations in response to "feast-and-famine" cycles. These adaptations have been associated with an increase in body fat, decrease in lean muscle mass and more rapid weight gain when food becomes plentiful (33). For many in impoverished communities, the experience of not having certain or adequate access to food often causes feelings of anxiety, stress and depression. This in turn leads to behaviours that increase the risk of becoming overweight and obese. Inherent in these behaviours are patterns of bingeing or overeating when food is available (as continued availability is uncertain), or choosing low-cost, energy-dense "comfort foods" rich in fat, sugar and salt (34). This is evident in the current study, with primary caregivers filling up on high sugar snacks, white bread and black coffee so their children and grandchildren have enough to eat. Some of these primary caregivers are already diabetic and on medication to control their blood sugar. This finding aligns with previous studies by showing how low income contributes to low dietary diversity, which in turn leads to poor dietary intake and micronutrient deficiencies $(32,35)$.

The women's perception of fathers provision for their children's dietary needs were significantly similar either the father was not present or present but unemployed. Mothers also stated that they were responsible for everyone's care in the house. Yet, despite women being breadwinners, the provision of emotional support to children remained the women's responsibility. Emotional support was an area where the men had very little involvement to no involvement, thereby reconfirming women's role as caregivers (5). If fathers were not present, mothers provided for the nutrition and dietary needs both financially and physically.

Page 11/16 
It is found that the depictions mothers use of their daily routines of nutritional care are so strongly reflected by a sense of 'morality of responsibility' which generally is the opposite of that descriptions of fathers' approaches (28). This was reflected by primary caregivers in the current study. The findings align with what is already known about the gendered division of family food work in Western societies, where 'the purchase and preparation of food for the family is the major responsibility of women' (28). Domestic involvement in children's diets and health remains more peripheral to contemporary fatherhood (36). Men's fulfilments of fatherhood does not necessitate participation in either feeding the family or managing children's routines, and broad conventional masculinity norms discourage fathers from engaging in healthy behaviours, including healthy eating $(37,38)$.

The benefit of parental nutrition education in improving children's health outcomes has been demonstrated (39). Information on healthy eating practices can support communities to alleviate poor health and fight against household food and nutrition insecurity in South Africa (40). Members of the community involved in this study needed specific guidance regarding food-related practices, which could be provided through workshops or practical demonstrations. Existing literature notes that workshops and demonstrations can benefit communities in pursuit of healthy diets (41). Additionally, such communities require guidance in understanding how to provide healthy meals on a budget, and ways to encourage children to eat the healthy meals provided.

This study found that fathers had a very limited influence on the nutritional provision of their families. This concurs with other studies, although as mentioned, limited research exists in South Africa on the role of fathers on the provision of specific nutritional care, precluding an understanding of the independent effects of fathers on young children's health behaviours (3). Additionally, there has not been a large focus placed on the resource constrained environment. While mothers and female primary caregivers may continue to largely structure these practices, fathers nonetheless help shape what families eat by providing financially and by the meals they prefer to eat.

This study clearly provides evidence that highlights the limitations of nutritional and dietary care fathers play in a low resource family setting. It also raises the express need that mothers, and caregivers have in wanting to provide nutritional meals for their families, as part of their understanding of their care responsibility. Limitations of the study include a small sample size only focused on Coloured mothers and grandmothers, which could present just one viewpoint on food choice and selection. Fathers were also not interviewed in order to understand their point of view. Future research should have a bigger sample size, explore these practices across geographies, and with diverse socio-demographics and family characteristics.

\section{Declarations}

\section{Ethics approval and consent to participate}

Ethical clearance was received for this study from the University of the Western Cape, Senate ethics committee with clearance number 14/10/34. Informed written consent was obtained from all participants 
in the study.

\section{Consent for publication}

Not applicable

\section{Availability of data and materials}

All data generated or analyzed during this study are included in this published article

\section{Competing interests}

The authors declare that they have no financial or personal relationship that may have influenced them writing this article

\section{Funding}

This work was supported by the National Research Foundation (NRF) South Africa

Grant number 110805

\section{Authors' contributions}

Not applicable

\section{Acknowledgements}

The authors would like to thank the participants for taking the time to be part of the workshop.

\section{References}

1. Lewaks A, Rich EG, Roman NV. The contribution of a South African intervention for fathers to child and family well-being: recommendations for practitioners. J Fam Stud [Internet]. 2018;1-14. Available from: https://doi.org/10.1080/13229400.2018.1500296

2. Yogman M, Garfield CF. Fathers' Roles in the Care and Development of Their Children: The Role of Pediatricians. Pediatrics [Internet]. 2016 Jul 1;138(1):e20161128. Available from: http://pediatrics.aappublications.org/content/138/1/e20161128.abstract

3. Walsh AD, Hesketh KD, van der Pligt P, Cameron AJ, Crawford D, Campbell KJ. Fathers' perspectives on the diets and physical activity behaviours of their young children. PLoS One. 2017; 12(6):e0179210.

4. Wells MB. Literature review shows that fathers are still not receiving the support they want and need from Swedish child health professionals. Acta Paediatr. 2016 Sep;105(9):1014-23.

5. Seepamore BK. Distance parenting - implications for social work practice. Vol. 52, Social Work . scieloza ; 2016. p. 571-88. 
6. Holborn, L. \& Eddy G. First steps to healing the South African family. Johannesburg: South African Institute of Race Relations; 2011.

7. Heilman B, Levtov R, van der Gaag N, Hassink A A, G B. State of the worlds fathers. Time for action [Internet]. Washington, D.C.; 2017. Available from: https://men-care.org/wpcontent/uploads/sites/3/2017/06/PR017004_REPORT-Post-print-June9-WEB-2.pdf

8. Hatch M, Posel D. Who cares for the children? A quantitative study of childcare in South Africa. J Dev South Africa,. 2018;35:267-82.

9. Statistics South Africa. General household survey [Internet]. 2014. Available from: http://www.statssa.gov.za/publications/P0318/P03182014.pdf

10. Statistics South Africa. General household survey. 2016.

11. Freeks F. Responding to the challenge of father absence and fatherlessness in the South African context: A case study involving concerned fathers from the North West Province. Stellenbosch Theol J. 2017 Aug 8;3:89-113.

12. Richter L, Chikovore J, Makusha T. The status of fatherhood and fathering in South Africa. Child Educ. 2010;86(6):360-5.

13. South African Social Service Agency (SASSA). South African Social Service Agency Factsheet [Internet]. Factsheet. 2017 [cited 2018 Sep 18]. Available from:

https://africacheck.org/factsheets/separating-myth-from-reality-a-guide-to-social-grants-in-southafrica/ \%OA

14. LeVine RA. Human parental care: Universal goals, cultural strategies, individual behavior. In: LeVine RA, Miller PM, West MM, editors. Parental Behavior in Diverse Societies New Directions for Child Development. San Francisco: Jossey-Bass; 1988.

15. Meintjes H, Hall K, Sambu W. Demography of South Africa's children. South African Child Gauge. Cape town , South Africa; 2015.

16. Daniel C. Economic constraints on taste formation and the true cost of healthy eating. Soc Sci Med. 2016 Jan;148:34-41.

17. Lipowska M, Lipowski M, Jurek P, Jankowska AM, Pawlicka P. Gender and Body-Fat Status as Predictors of Parental Feeding Styles and Children's Nutritional Knowledge, Eating Habits and Behaviours. Int J Environ Res Public Health. 2018 Apr;15(5).

18. Smith JA, Rocke KD, Charles SM, Chang SM, Wright AS, Walker SP, et al. The role of fathers in overweight prevention: an analysis of a Caribbean cohort. Glob Heal Epidemiol Genomics [Internet]. 2018/08/28. 2018;3:e15. Available from: https://www.cambridge.org/core/article/role-of-fathers-inoverweight-prevention-an-analysis-of-a-caribbean-cohort/F5D7FD79C98CE84F868E4B471697832E

19. Furlong S. South Africa's real nutrition problems. GroundUP [Internet]. 2015 Oct 2; Available from: https://www.groundup.org.za/article/south-africas-real-nutritionproblems_3355/\#sthash.9FRwASoc.dpuf

20. Henning E. Finding your way in qualitative research. Pretoria: Van Schaik; 2004. 124 p. 
21. Mullagee F, Bruce D. BUILDING A GOOD NATION IN MANENBERG: A case study of the Manenberg Community Work Programme. 2015.

22. City of Cape town. Manenberg District Census [Internet]. Cape town, South Africa; 2011. Available from: http://resource.capetown.gov.za/documentcentre/Documents/Maps and statistics/2011_Census_CT_Suburb_Manenberg_Profile.pdf

23. Anderson B. 'Coloured' boys in 'trouble': an ethnographic investigation into the constructions of Coloured working-class masculinities in a high school in Wentworth, Durban. University of KwaZuluNatal.; 2009.

24. Anderson B. I'm Not So into Gangs Anymore. I've Started Going to Church Now: Coloured Boys Resisting Gangster Masculinity. Agenda Empower women Gend equity. 2011;23(80):55-67.

25. Salo E. Mans is Ma Soe: Ganging practices in Manenberg, South Africa and the ideologies of masculinity, gender and generational relations [Internet]. Essay: African Gender Institute of the University of Cape Town. 2011. Available from:

http://www.csvr.org.za/images/cjc/mans_is_ma_soe.pdf

26. Moolman B. The reproduction of an 'ideal' masculinity through gang rape on the Cape Flats: understanding some issues and challenges for effective redress. Agenda [Internet]. 2004 Jan 1;18(60):109-24. Available from:

https://www.tandfonline.com/doi/abs/10.1080/10130950.2004.9674549

27. Braun V, Clarke V. Using thematic analysis in psychology. Qualitative Research in Psychology [Internet]. 2006 [cited 2019 Apr 4]. Available from: http://www.qualresearchpsych.com

28. Tanner C, Petersen A, Fraser S. Food, fat and family: Thinking fathers through mother's words. Womens Stud Int Forum. 2014;44:209-19.

29. Andreyeva T, Tripp AS, Schwartz MB. Dietary Quality of Americans by Supplemental Nutrition Assistance Program Participation Status: A Systematic Review. Am J Prev Med. 2015 Oct;49(4):594604.

30. Development Initiatives. Global Nutrition Report: Shining a light to spur action on nutrition [Internet]. Bristol; 2018. 3-165 p. Available from: http://ebrary.ifpri.org/cdm/ref/collection/p15738coll2/id/128484

31. FAO, IFAD, UNICEF W and W. State of Food Security and Nutrition in the World 2019. Building climate resilience for food security and nutrition. Rome; 2018.

32. Oldewage-Theron WH, Dicks EG, Napier CE. Poverty, household food insecurity and nutrition: coping strategies in an informal settlement in the Vaal Triangle, South Africa. Public Health. 2006 Sep;120(9):795-804.

33. Ghattas H. Food security and nutrition in the context of nutrition transition [Internet]. Rome, FAO.; 2014. Available from: http://www.fao.org/3/a-i3862e.pdf

34. Bruening M, MacLehose R, Loth $K$, Story M, Neumark-Sztainer D. Feeding a family in a recession: food insecurity among Minnesota parents. Am J Public Health [Internet]. 2012/01/19. 2012 Mar;102(3):520-6. Available from: https://www.ncbi.nlm.nih.gov/pubmed/22390517 
35. Schönfeldt HC, Gibson N, Vermeulen H. NEWS AND VIEWS: The possible impact of inflation on nutritionally vulnerable households in a developing country using South Africa as a case study. Nutr Bull [Internet]. 2010 Sep 1;35(3):254-67. Available from: https://doi.org/10.1111/j.14673010.2010.01837.x

36. Yavorsky JE, Dush CMK, Schoppe-Sullivan SJ. The Production of Inequality: The Gender Division of Labor Across the Transition to Parenthood. J Marriage Fam. 2015 Jun;77(3):662-79.

37. Courtenay WH. Constructions of masculinity and their influence on men's well-being: a theory of gender and health. Soc Sci Med. 2000 May;50(10):1385-401.

38. Gough B, Conner MT. Barriers to healthy eating amongst men: a qualitative analysis. Soc Sci Med. 2006 Jan;62(2):387-95.

39. Dev DA, Byrd-Williams C, Ramsay S, McBride B, Srivastava D, Murriel A, et al. Engaging Parents to Promote Children's Nutrition and Health. Am J Health Promot. 2017 Mar;31(2):153-62.

40. Davids A, Nkomo N, Mfecane S, Skinner D, Ratele K. Multiple and Vulnerabilities: Qualitative data for the study of orphans and vulnerable children in South Africa. HSRC Press. Cape town , South Africa; 2008.

41. Faber M, Witten C, Drimie S. Community-based agricultural interventions in the context of food and nutrition security in South Africa. South African J Clin Nutr [Internet]. 2010 Nov 27;24(1 SE-Review Articles). Available from: http://www.sajcn.co.za/index.php/SAJCN/article/view/461 